\title{
Endothelial deletion of murine Jag1 leads to valve calcification and congenital heart defects associated with Alagille syndrome
}

\author{
Jennifer J. Hofmann 1,*, Anais Briot ${ }^{2}$, Josephine Enciso ${ }^{3}$, Ann C. Zovein ${ }^{2,3, \neq}$, Shuxun Ren ${ }^{4}$, Zhen W. Zhang ${ }^{5}$, \\ Freddy Radtke ${ }^{6}$, Michael Simons ${ }^{5}$, Yibin Wang ${ }^{4}$ and M. Luisa Iruela-Arispe ${ }^{1,2, \S}$
}

\begin{abstract}
SUMMARY
The Notch signaling pathway is an important contributor to the development and homeostasis of the cardiovascular system. Not surprisingly, mutations in Notch receptors and ligands have been linked to a variety of hereditary diseases that impact both the heart and the vasculature. In particular, mutations in the gene encoding the human Notch ligand jagged 1 result in a multisystem autosomal dominant disorder called Alagille syndrome, which includes tetralogy of Fallot among its more severe cardiac pathologies. Jagged 1 is expressed throughout the developing embryo, particularly in endothelial cells. Here, we demonstrate that endothelialspecific deletion of Jag1 leads to cardiovascular defects in both embryonic and adult mice that are reminiscent of those in Alagille syndrome. Mutant mice display right ventricular hypertrophy, overriding aorta, ventricular septal defects, coronary vessel abnormalities and valve defects. Examination of mid-gestational embryos revealed that the loss of Jag1, similar to the loss of Notch1, disrupts endothelial-to-mesenchymal transition during endocardial cushion formation. Furthermore, adult mutant mice exhibit cardiac valve calcifications associated with abnormal matrix remodeling and induction of bone morphogenesis. This work shows that the endothelium is responsible for the wide spectrum of cardiac phenotypes displayed in Alagille Syndrome and it demonstrates a crucial role for Jag1 in valve morphogenesis.
\end{abstract}

KEY WORDS: Aortic valves, Cardiac valves, EndMT, Notch, Mouse

\section{INTRODUCTION}

As the first functional organ during embryonic development, the heart is formed through a complex series of multi-lineage cell interactions that coordinate proliferation, migration and differentiation (Olson, 2006; Srivastava, 2006). The requirement for a highly regulated balance of heterotypic signaling events is evident after one or more genes are lost, leading to dire consequences for cardiac development. In fact, congenital heart malformations account for nearly one-third of all major congenital defects, which remain the leading cause of infant mortality in the United States (Mathews and MacDorman, 2011; van der Linde et al., 2011). Thus, a concrete understanding of the regulatory circuitry of interactions during cardiac development is essential. Over the last two decades, significant strides have been made towards accomplishing this goal; however, the picture is far from complete.

\footnotetext{
${ }^{1}$ Molecular Biology Institute, University of California, Los Angeles, CA 90095, USA. ${ }^{2}$ Department of Molecular, Cellular, and Developmental Biology, University of California, Los Angeles, CA 90095, USA. ${ }^{3}$ Division of Neonatology, Department of Pediatrics, University of California, Los Angeles, CA 90095, USA. ${ }^{4}$ Division of Anesthesiology, Department of Medicine, University of California, Los Angeles, CA 90095, USA. ${ }^{5}$ Section of Cardiovascular Medicine, Department of Internal Medicine, Yale University School of Medicine, New Haven, CT 06520-8017, USA. ${ }^{6}$ Ecole Polytechnique Fédérale de Lausanne, Swiss Institute for Experimental Cancer Research, Epalinges, Switzerland.

*Current Address: Department of Medical Biochemistry and Biophysics, Division of Vascular Biology, Karolinska Institutet, 17177 Stockholm, Sweden

${ }^{\ddagger}$ Current Address: UCSF Cardiovascular Research Institute and Division of Neonatology, Dept. of Pediatrics, 555 Mission Bay Blvd South, San Francisco, CA 94143-3120, USA

${ }^{\S}$ Author for correspondence (arispe@mcdb.ucla.edu)
}

Accepted 5 September 2012
Several congenital vascular diseases are associated with mutations in the Notch signaling pathway, including Alagille syndrome (AGS), cerebral autosomal dominant arteriopathy with subcortical infarcts and leukoencephalopathy (CADASIL) and calcific aortic valve disease (Gridley, 2010; High and Epstein, 2008; MacGrogan et al., 2011; Nemir and Pedrazzini, 2008; Penton et al., 2012). The initial link between the Notch ligand jagged 1 (Jag1) and heart development was established in 1997, with the simultaneous discovery by two groups that AGS was caused by mutations in the human JAG1 gene (Penton et al., 2012). AGS is an autosomal dominant multisystem disorder that leads to paucity of intrahepatic bile ducts, as well as cardiac, skeletal, renal, facial and ocular abnormalities. Subsequently, it was found that although the majority of AGS patients had mutations in $J A G 1$, a small subset of individuals harbored mutations in the gene encoding the NOTCH2 receptor (McDaniell et al., 2006).

Over the last decade, many investigations have focused on mapping $J A G 1$ mutations and determining its expression patterns to understand better the function of this gene in the context of the disease (Bauer et al., 2010; Crosnier et al., 2000; Eldadah et al., 2001; Gridley, 2010; High and Epstein, 2008; Jones et al., 2000; Krantz et al., 1999; Loomes et al., 1999; McDaniell et al., 2006; Raas-Rothschild et al., 2002; Rutenberg et al., 2006). Elegant studies using cell-specific loss of function have revealed the involvement of Jagl in the closure of the ductus arteriosus and in several aspects of cardiac morphogenesis (Feng et al., 2010; High et al., 2009; Manderfield et al., 2012). Particularly during heart development, Jagl is expressed in the coronary arteries, secondary heart field and neural crest cells (de la Pompa and Epstein, 2012; Penton et al., 2012). Inactivation of the gene within these compartments yields cardiac outflow and aortic arch artery defects resulting in lethality by embryonic day (E) 10.5 (High et al., 2009; 
Manderfield et al., 2012). The defects, however, do not recapitulate those displayed by patients with AGS or aortic valve disease. It is likely that the severe cardiac abnormalities displayed by these murine models might also result in lethality in humans.

To examine the contribution of endothelial Jagl at later developmental time points than those evaluated previously, we used a VE-Cadherin-Cre-mediated excision of the gene. The resultant Jagl mutant mice displayed a spectrum of cardiac defects that were highly reminiscent of those present in AGS, including ventricular septal defects (VSD), overriding aorta, right ventricular hypertrophy, valve malformations and stenosis. Through a combination of genetic, histological and organotypic ex vivo studies, we showed that the loss of Jagl in the endothelium leads to a blockage of endothelial-to-mesenchymal transformation (EndMT), an essential step in formation of the atrioventricular (AV) valves and septum intermedium. In addition, at later stages of heart development, Jagl is required for proper valve remodeling. Absence of Jag1 results in myxomatous valves owing to the accumulation of uncleaved versican. Furthermore, $50 \%$ of mutant mice developed valve calcifications with accumulation of bone between 5 and 13 months of age. These findings indicate that the cardiac defects manifested in AGS and other valve-specific defects are largely endothelial derived and are rooted in defective Jag1 signaling during early embryonic development.

\section{MATERIALS AND METHODS}

Animals

VE-Cadherin-Cre (Alva et al., 2006), Jag $1^{\text {floxflox }}$ (Mancini et al., 2005) and Notch $1^{\text {floxfllox }}$ (Radtke et al., 1999) mice were previously described and bred for six generations on a C57BL/6J background. These mice were also crossed to R26R (Soriano, 1999) or TNR1 Notch reporter mice (Duncan et al., 2005). Embryos were collected using timed matings. PCR analysis on genomic DNA from embryos or tails was used for genotyping.

\section{Tissue collection and imaging}

Standard protocols for staining, immunocytochemistry and imaging were used with paraformaldehyde- or glutaraldehyde-fixed tissues (Alva et al., 2006). $\beta$-Galactosidase staining was performed as previously described (Alva et al., 2006). Standard protocols for Hematoxylin and Eosin (H\&E), Nuclear Fast Red, Alizarin Red S and von Kossa staining were used for cardiac slides. Antibodies used were: anti-rat jagged 1 (R\&D Systems; 1:25), anti-PECAM1 (gift of Joseph A. Madri, Yale, New Haven, CT, USA; 1:250), anti-PECAM1 (BD Pharmingen; 1:250), anti- $\alpha$ smooth muscle actin-FITC ( $\alpha$ SMA; Sigma; 1:800), anti-VersicanGAG $\beta$ (Chemicon; 1:100) and anti-versican V0/V1 (DPEAAE; Thermo Scientific; 1:50). For non-fluorescent immunostaining, tissues were incubated with primary antibodies and biotinylated secondary antibodies (Jackson ImmunoResearch Laboratories), and treated with Vectastain ABC Kit reagents (Vector Labs) followed by DAB substrate (Vector Labs). Alexa Fluor-conjugated (Invitrogen) or FITC-conjugated (Jackson ImmunoResearch Laboratories) fluorescent secondary antibodies were used and DAPI (Invitrogen; 1:1000) or TOPRO-3 (Molecular Probes; 1:300) were used for counterstaining. Tissues were analyzed using a Zeiss LSM multiphoton microscope (Carl Zeiss AG) and image processing was carried out using Adobe Photoshop CS5 (Adobe Systems).

\section{Cardiac physiology and imaging}

Mice were anesthetized with $2 \%$ isofluorane, and heart rate and body temperature were monitored during Doppler and 2D imaging. For microcomputed tomography $(\mu \mathrm{CT})$ imaging, hearts were perfused with $1 \times \mathrm{PBS}$, fixed with $4 \%$ paraformaldehyde, stained with a contrast agent, and scanned at $10 \mu \mathrm{m}$ isometric voxel resolution at 200 mseconds exposure time (volumetric $\mu \mathrm{CT}$ scanner $\mu \mathrm{CT} 40$ from ScanCo Medical, Numira Biosciences, Salt Lake City, UT, USA; Virtual Histology). Doppler and 2D imaging of the parasternal long-axis and short axis were performed by echocardiography using a Vevo 770 Imaging System (Visual Sonics,
Toronto, Canada) that was equipped with the RMV-707B transducer (30 Mhz $12.7 \mathrm{~mm}$ focal length), with the placement of the Doppler probe at $65^{\circ}$ with coronal plane as described (Liao et al., 2001).

\section{Cardiac explants}

E9.5 atrioventricular cardiac cushions (20-28 somites) were dissected and explanted as described (Camenisch et al., 2002; Runyan and Markwald, 1983). $N$-[N-(3,5-difluorophenacetyl)-L-alanyl]-S-phenylglycine t-butyl ester (DAPT; $10 \mu \mathrm{M}$ or $50 \mu \mathrm{M}$, diluted in DMSO) or $0.2 \%$ DMSO (controls) was added to wild-type explants. Media, with/without DAPT and DMSO, was changed daily. Explants were photographed in 12-hour increments. Samples were stained with anti- $\alpha$ SMA, anti-PECAM1 and TOPRO 3 and imaged. For treatment with $\gamma$-secretase inhibitors, wild-type explants were adhered to type I collagen gels for a minimum of 6 hours before adding DAPT or DMSO. Two independent observers counted total nuclei embedded within the collagen matrix in selected areas and the percentage of transformed mesenchymal cells $\left(\alpha \mathrm{SMA}^{+}, \mathrm{PECAM}^{-}\right.$ expression). $P$ was calculated using Student's two-tailed $t$-test for paired comparisons and one-way ANOVA with the Bonferroni correction was applied when analyzing multiple (three) groups.

\section{Quantitative real time PCR}

Postnatal day (P) 10 mouse outflow tract (OFT) and AV valves were isolated under a dissecting microscope. Total RNA from OFT and AV valves was purified using the RNeasy Mini Kit (QIAGEN, Valencia, CA, USA). Complementary DNA synthesis from 15-25 ng of total RNA was performed using SuperScript III (Invitrogen). Quantitative RT-PCR was then performed on a DNA Engine Opticon 2 Real-Time Cycler PCR (MJ Research; Biorad, Hercules, CA, USA) using the RT ${ }^{2}$ SYBR Green qPCR Master Mix (SABiosciences; QIAGEN). Primer sequences are listed in supplementary material Table S1. Results were analyzed with MJ Opticon Monitor Analysis software Version 3.1 (MJ Research; Biorad). Each reaction was run in duplicate and normalized with the housekeeping gene Hprt. Data are presented relative to mean $\Delta \mathrm{CT}$ of wild-type animals. $P$ was calculated using the Student-Fisher test.

FACS, western blot analysis and immunoprecipitation

Endothelial cells were fluorescence-activated cell sorted (FACS) from E12.5, E13.5, E15.5, E17.5 and P10 J1 ${ }^{\mathrm{WT}}$ and $\mathrm{J} 1{ }^{\mathrm{ECKO}}$ embryos using antiPECAM antibodies, as previously described (Zovein et al., 2010). All samples were stained for viability with 7-AAD (BD Pharmingen) and analyzed on a FACSCaliber with the appropriate isotype controls. Endothelial cell protein lysate from $\mathrm{J} 1^{\mathrm{WT}}$ and $\mathrm{J} 1^{\mathrm{ECKO}}$ embryos were separately pooled for each time point and quantified for protein concentration (DC protein, BioRad). Then samples were pre-cleared with beads bound to secondary antibodies and incubated overnight with anti-Jag1 (Santa Cruz Biotechnology) (1:800). Recovery of the immunocomplexes and western blot were carried out as previously described (Chen et al., 2010).

\section{RESULTS}

\section{Temporal loss of Jag1 after endothelial-specific deletion}

We have previously reported that an endothelial-specific deletion of Jag1 using a VE-Cadherin-Cre line, termed Jag1 endothelial cell knockout $\left(\mathrm{J}^{\mathrm{ECKO}}\right)$ mice, yielded viable mutants with normal bile duct development, but defective vascular smooth muscle cell recruitment (Hofmann et al., 2010; Scheppke et al., 2012). By contrast, previous reports of Jagl-specific endothelial deletion resulted in embryonic lethality at E10.5 (Benedito et al., 2009; High et al., 2008). We suspected that these differences might relate to the timing/efficiency of deletion conveyed by each Cre line. In fact, evaluation of temporal loss of Jag1 in $\mathrm{J} 1^{\mathrm{ECKO}}$ mice demonstrated sporadic loss of the protein by E10.5 (Fig. 1A, arrowheads). By P0, expression of Jag1 protein was largely lost in the endothelium of the dorsal aorta (Fig. 1A, arrowheads), but was retained within the smooth muscle cells of the vascular wall (Fig. 1A, arrows). 

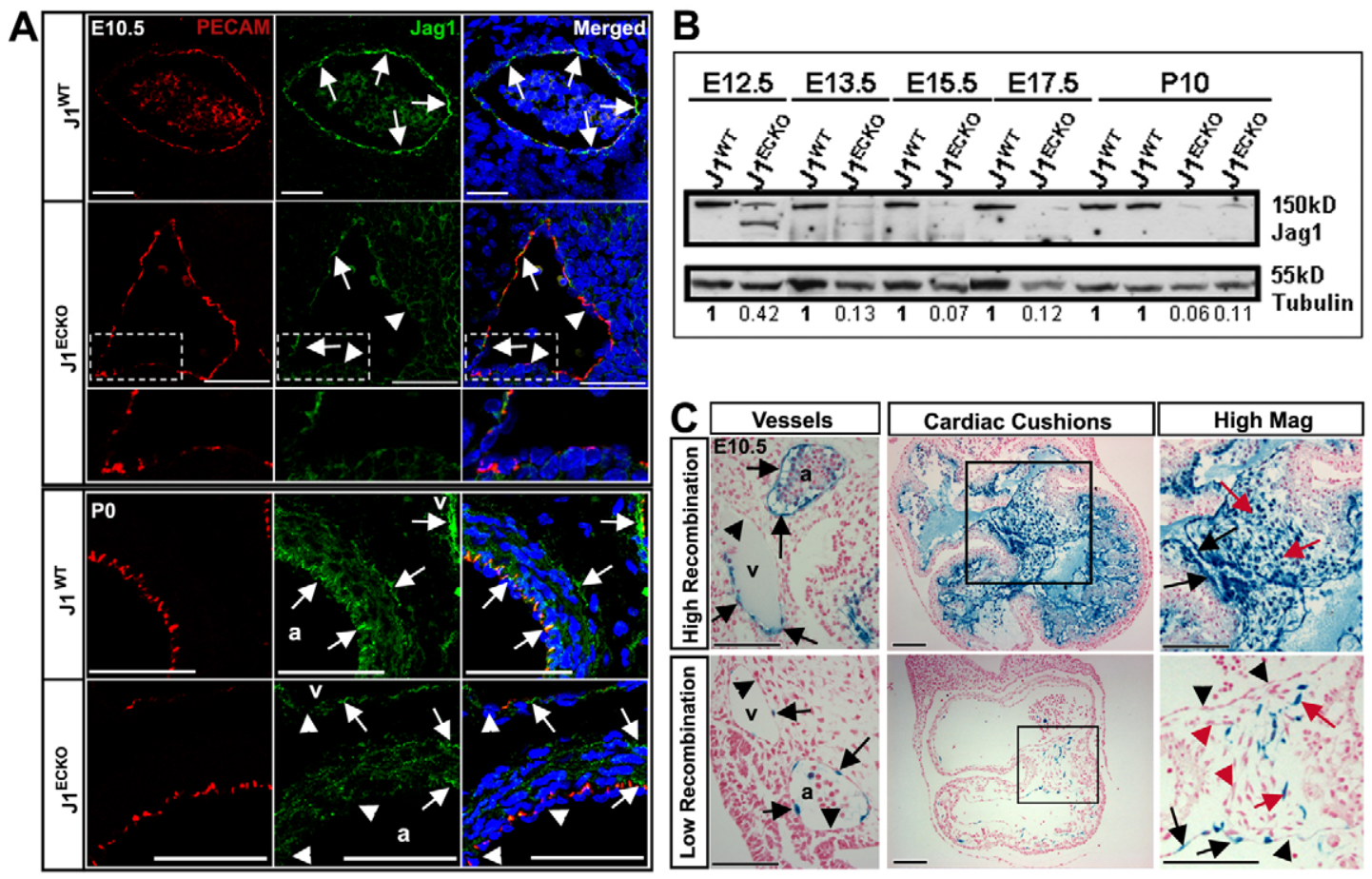

Fig. 1. Deletion of Jag1 in the endothelium. (A) Jag1 immunostaining (green) in the endothelium (red) of J1WT and J1ECKO mice. Mosaic Jag1 expression in E10.5 J1 $1^{\mathrm{ECKO}}$ vessels compared with $\mathrm{J}{ }^{\mathrm{WT}}$ mice, with areas of Jag1 loss (arrowheads) adjacent to areas of Jag1 expression (arrows). By PO, endothelial Jag1 deletion was highly penetrant (arrowheads) in J1ECKO mice, whereas Jag1 was maintained in veins and some smooth muscle cells (arrows). (B) Western blot on fluorescence-activated cell sorting (FACS)-isolated endothelial cells from J1 ${ }^{\mathrm{WT}}$ and J1 ${ }^{\mathrm{ECKO}}$ embryos at progressive developmental stages showed decreases in Jag1 levels over time in J1 $1^{\mathrm{ECKO}}$ mice compared with J1WT. Tubulin levels were used as loading controls. Several faint lower bands in embryonic J1 ${ }^{\mathrm{ECKO}}$ samples were degradation/processing fragments not seen in other equivalent samples. (C) Evaluation of VE-Cadherin-Cre activity at E10.5 revealed animals with high (upper panels) and low (lower panels) recombination, as shown by $\beta$-galactosidase staining (blue). Arrows indicate recombined cells and arrowheads non-recombined endothelium. Cardiac cushions at high magnification show both recombined (red arrows) and non-recombined (red arrowheads) mesenchymal cells resulting from EndMT cells. a, atrium; v, ventricle. Scale bars: 50 $\mu \mathrm{m}$ in $\mathrm{A} ; 100 \mu \mathrm{m}$ in $\mathrm{C}$.

To quantify more rigorously Jag 1 changes in $\mathrm{J} 1^{\mathrm{ECKO}}$ mice, we performed western blot analysis on lysates from endothelial cells isolated at different stages of development (Fig. 1B). By E12.5, $\sim 60 \%$ of Jag 1 protein was lost, with a more significant decrease soon after at E13.5 (close to 90\%), compared with littermate controls (Fig. 1B). The use of the Rosa26;lacZ reporter line (R26R) (Soriano, 1999) further revealed the temporal activity of $V E$-Cadherin-Cre at the cellular level and confirmed varying levels of Cre recombination at E10.5. Two extreme examples are shown in Fig. 1C. In mice with high recombination (Fig. 1C, upper panel), endothelial cells of major arteries were almost completely $\beta$-galactosidase-positive (Fig. 1C, arrows), with veins slightly less so (Fig. 1C, arrowheads). The endothelial cells (Fig. 1C, black arrows) and endothelial-derived mesenchymal cells of the cardiac cushions (Fig. 1C, red arrows) also showed a high degree of recombination. By contrast, mice with low levels of Cre recombination at a similar time point, exhibited only a few $\beta$-galactosidase-positive cells in the vessels and cardiac cushions of the heart (Fig. 1C, lower panels, black arrows). In fact, the majority of the arterial and venous endothelium, as well as the endocardium, was $\beta$-galactosidase negative (Fig. 1C, black arrowheads), whereas few $\beta$-galactosidase-positive mesenchymal cells (Fig. 1C, red arrows) were present alongside $\beta$ galactosidase-negative cells (Fig. 1C, red arrowheads). The variable penetrance of this particular VE-Cadherin-Cre in early development (E10.5), as well as the mixed C57B16 F6 background of the mice, explain the wide range of lethality observed in $\mathrm{J} 1{ }^{\mathrm{ECKO}}$ mice, reconcile these findings with previous groups and, more importantly, provide an opportunity to explore the requirement for Jagl in endothelial cells at different developmental stages and to determine the relevance of Jag1 deletion.

\section{Morphology and physiological analysis of adult J1ECKO hearts revealed cardiac defects}

Although viable $\mathrm{J} 1{ }^{\mathrm{ECKO}}$ mice were frequently recovered, several pups and adult mice succumbed to sudden death. A closer examination of surviving adult $\mathrm{J} 1{ }^{\mathrm{ECKO}}$ hearts showed that mutant mice displayed a range of cardiac anomalies (Fig. 2). This was consistent with the mosaic deletion pattern of Jag1 early in development and mimicked the cardiac components of AGS. However, other organs frequently impacted by AGS, including the liver, eye, kidney and vertebrae, were not affected (Hofmann et al., 2010) (data not shown).

Common features in many adult $\mathrm{J} 1^{\mathrm{ECKO}}$ animals were macroscopic aberrations in heart morphology, including thin or disorganized coronary vessels (Fig. 2A, arrowheads), dilation noted near the apex of the heart (Fig. 2A, arrows) and abnormal positioning of the aorta and pulmonary trunk (not shown). Echocardiographic evaluations of a sampling of adult mice showed that $\mathrm{J} 1{ }^{\mathrm{ECKO}}$ mice had increased systolic blood velocity with severe regurgitation at the pulmonic valve, compared with Cre-negative 

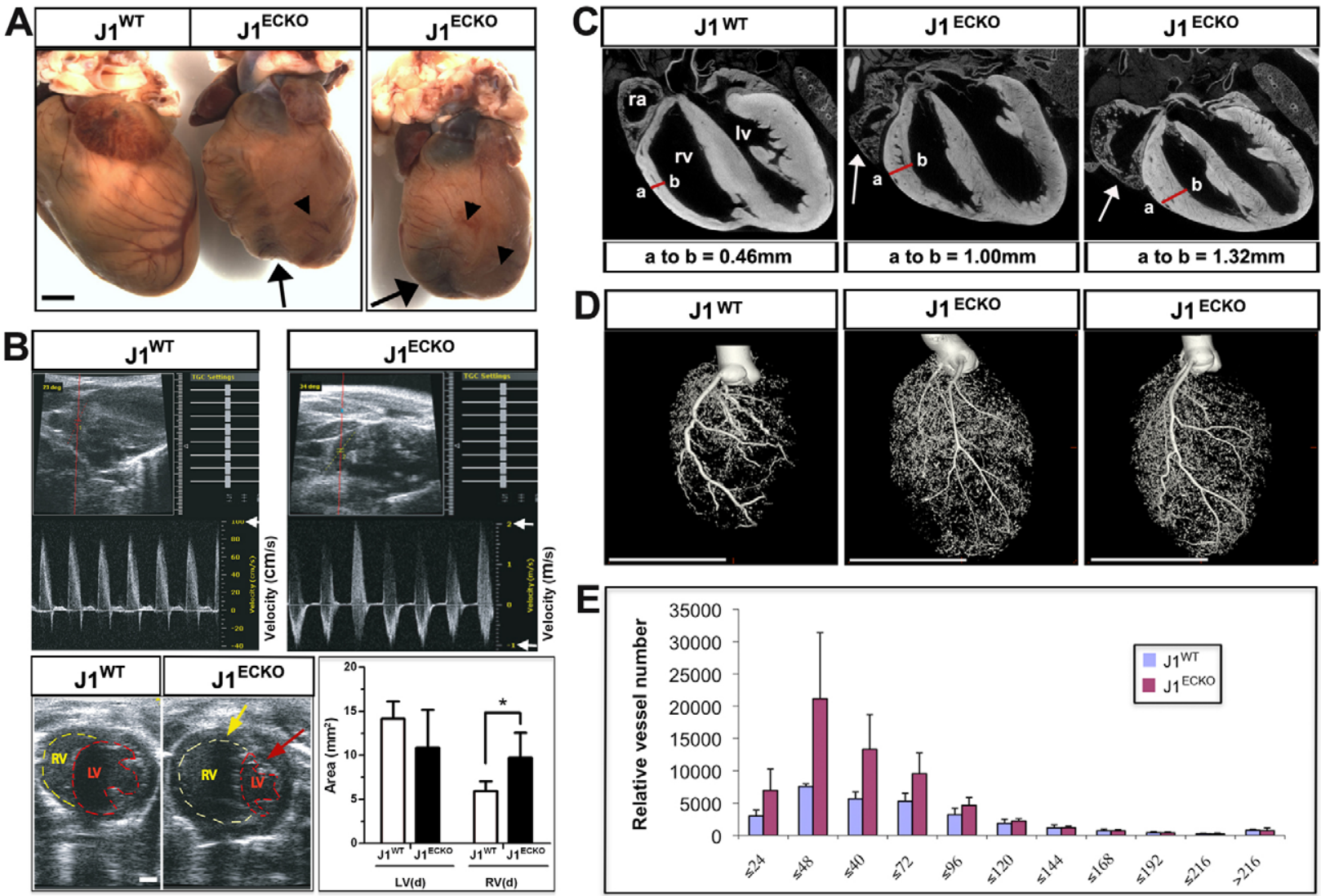

Fig. 2. Cardiac defects in adult Jag1 endothelial mutants. (A) $\mathrm{J}_{1} \mathrm{ECKO}$ mice demonstrated morphological defects in the adult heart. Hearts from mutant mice frequently exhibited defective coronary vessel branching (arrowheads) and abnormal heart structure near the apex (arrows), suggesting dilation or right ventricular hypertrophy (arrows) $(n=20)$. (B) Representative 2D echo and Doppler images of adult male mice, measured near the right ventricular outflow tract, showed severe regurgitation at the pulmonary semilunar valve and an increase in systolic blood velocity during right ventricular ejection in $\mathrm{J} 1^{\mathrm{ECKO}}$ hearts. Note different scales of velocity (white arrows) in J1 ${ }^{\mathrm{WT}}$ ( $\mathrm{cm} / \mathrm{second}$ ) and $\mathrm{J1}$ ECKO $\left(\mathrm{m} / \mathrm{second}^{\text {) }}\right.$ measurements. The lower images of the same panel display a left parasternal transverse section with 2D measurement of adult hearts, demonstrating an increase in the right ventricular chamber (yellow dotted line and yellow arrow) and a decrease in the left ventricular chamber (red dotted line and red arrow) in J1 ${ }^{\mathrm{ECKO}}$ mice $(n=6)$ compared with J1 ${ }^{\mathrm{WT}}(n=6)$. Measurement of ventricular chamber area at diastolic demonstrated a significant increase in the size of $\mathrm{J} 1 \mathrm{ECKO}$ right ventricles ( $\left.{ }^{*} P=0.024\right)$. (C) $\mu \mathrm{CT}$ imaging of adult J1 ${ }^{\mathrm{WT}}$ and $\mathrm{J} 1 \mathrm{ECKO}$ hearts showed right ventricular hyperplasia in mutants, as per measurements of the right ventricular wall (red line between a and b). J1 ${ }^{\mathrm{ECKO}}$ hearts also showed enlarged right atria (arrows). (D) Additional $\mu \mathrm{CT}$ imaging of adult J1 $\mathrm{ECKO}$ hearts revealed increased coronary vessel density in many mice. (E) Quantification of vessel number according to vessel diameter of $\mathrm{J} 1 \mathrm{ECKO}^{\mathrm{E}}$ and $\mathrm{J} 1{ }^{\mathrm{WT}}$ hearts using $\mu \mathrm{CT}(n=11)$. IV, left ventricle; ra, right atrium; rv, right ventricle. Error bars represent s.d. Scale bars: $1 \mathrm{~mm}$ in $A, B ; 5 \mathrm{~mm}$ in $D$.

littermates, indicating valve stenosis (Fig. 2B, white arrows). Mutants also exhibited significant increases in right ventricle area and had right atrial and ventricular hypertrophy, noted with the use of cardiac micro-computed tomography $(\mu \mathrm{CT})$ imaging (Fig. $2 \mathrm{~B}, \mathrm{C})$. Thickening of the right ventricular wall was probably a compensation due to the increased pressure load of the right ventricle caused by pulmonary outflow tract narrowing or defective valves, common in AGS patients (McElhinney et al., 2002; Otto, 2009). Additionally, $\mu \mathrm{CT}$ imaging revealed greater density and excessive branching of coronary vessels in many of the $\mathrm{J}_{1}^{\mathrm{ECKO}}$ hearts (Fig. 2D,E), as would be expected for a Notch loss-offunction phenotype, even though the data did not reach significance.

\section{Embryonic and neonatal cardiac defects in J1ECKO mice}

Evaluation of $\mathrm{J} 1{ }^{\mathrm{ECKO}}$ hearts from embryos and neonates was also consistent with AGS-related cardiac defects, including many hallmarks of tetralogy of Fallot (TOF): VSDs, overriding aorta and right ventricular hypertrophy, as well as valve pathology (Table 1; Fig. 3). Upon gross evaluation, the morphology of neonatal $\mathrm{J} 1{ }^{\mathrm{ECKO}}$ hearts was often striking, with anomalies in the structure (Fig. 3A, arrows) and patterning of the coronary vasculature, including fragility and hemorrhaging (Fig. 3A, arrowheads), as well as outflow tract defects (Fig. 3B, dotted lines).

Histological analysis revealed VSDs (Fig. 3C,D, arrows) and large, hyperplastic (myxomatous) valves in $\mathrm{J}^{\mathrm{ECKO}}$ mice (Fig. $3 \mathrm{C}$, asterisk). The ventricular septum of mice typically divides the ventricles at E13.5; however, examination of embryonic $\mathrm{J} 1{ }^{\mathrm{ECKO}}$ hearts showed an incomplete septum at E14.5 (Fig. 3D, arrow). Bulges near the valve annulus were seen in some neonatal $\mathrm{J} 1{ }^{\mathrm{ECKO}}$ mice with otherwise normal valve leaflet development (Fig. 3E, arrow). Macroscopic analysis of 46 embryonic or neonatal $\mathrm{J} 1{ }^{\mathrm{ECKO}}$ mice showed that one or more cardiac abnormalities were present in $47.8 \%$ of the mice evaluated, with overriding aorta being the most common defect (Table 1). 
Table 1. Macroscopic embryonic and neonatal cardiac defects in J1 ${ }^{\mathrm{ECKO}}$ mice

\begin{tabular}{|c|c|c|}
\hline & Number of animals & Percentage of $J 1{ }^{\mathrm{ECKO}}$ mice affected \\
\hline $\mathrm{J1}^{\mathrm{ECKO}}$ animals with at least one cardiac defect & 22 & 47.8 \\
\hline Overriding aorta & 14 & 30.4 \\
\hline Abnormal coronary vessels & 6 & 13 \\
\hline Enlarged heart & 3 & 6.5 \\
\hline Enlarged right ventricle & 2 & 4.3 \\
\hline Abnormal outflow tract & 1 & 2.2 \\
\hline Non-obvious macroscopic defect & 24 & 52.2 \\
\hline Total number of J1 ${ }^{\mathrm{ECKO}}$ animals examined & 46 & - \\
\hline
\end{tabular}

Some form of cardiac defect, including overriding aorta, abnormal coronary vessel patterning, enlarged heart and enlarged right ventricle, was shown in $47.8 \%$ of embryonic and neonatal J1ECKO mice from 16 litters. Overriding aorta was the most common macroscopic defect affecting these mutant mice.

\section{Defects in endocardial cushion formation in $\mathrm{J1}_{1}^{\mathrm{ECKO}}$ and N1ECKO mice}

Cushion development requires a specialized form of epithelial-tomesenchymal transition (EMT) called endothelial-to-mesenchymal transformation (EndMT), a process that is initiated in the mouse at E9.5 (de la Pompa and Epstein, 2012). The events associated with EndMT include: endocardial cell delamination from a flattened monolayer, transformation of endothelial cells into mesenchymal cells, migration and invasion into the cardiac jelly, and rapid proliferation (Armstrong and Bischoff, 2004; Eisenberg and Markwald, 1995; Person et al., 2005; Schroeder and Listgarten, 2003). Given the phenotype of $\mathrm{J}^{\mathrm{ECKO}}$ mice, we sought to examine the hearts of $\mathrm{J} 1{ }^{\mathrm{ECKO}}$ mice in greater detail, and compared them with $V E$-Cadherin-Cre; Notch flox/flox mice $\left(\mathrm{N}^{\mathrm{ECKO}}\right)$ mice during cardiac cushion remodeling at E10.5 (Fig. 4).
The AV cushions of $\mathrm{J}^{\mathrm{ECKO}}$ hearts at E10.5 showed rounded endocardial-derived cells (Fig. 4B,C, arrowheads) that accumulated at the cushion interface (Fig. 4B,C, red arrows) and less dense, hypoplastic areas present within the cushions (Fig. $4 \mathrm{~B}, \mathrm{C}$, open arrows). This was in contrast to the high transformation of cushions from $V E$-Cadherin-Cre; $26 R$ hearts at E10.5 (Fig. 4A). Overall, EndMT was at least temporally delayed in the $\mathrm{J}_{1}^{\mathrm{ECKO}}$ hearts, with fewer transformed mesenchymal cells present in the AV cushions.

Consistent with published findings on global deletion of Notch1 or pharmacological inactivation of the Notch pathway (Fischer et al., 2007; Timmerman et al., 2004), endothelial deletion of Notch1 in $\mathrm{N} 1^{\mathrm{ECKO}}$ hearts also resulted in EndMT arrest (Fig. 4D) and phenocopied the $\mathrm{J} 1^{\mathrm{ECKO}}$ hearts, with rounded cells present at the cushion interface (Fig. 4D, red arrows) and areas with few
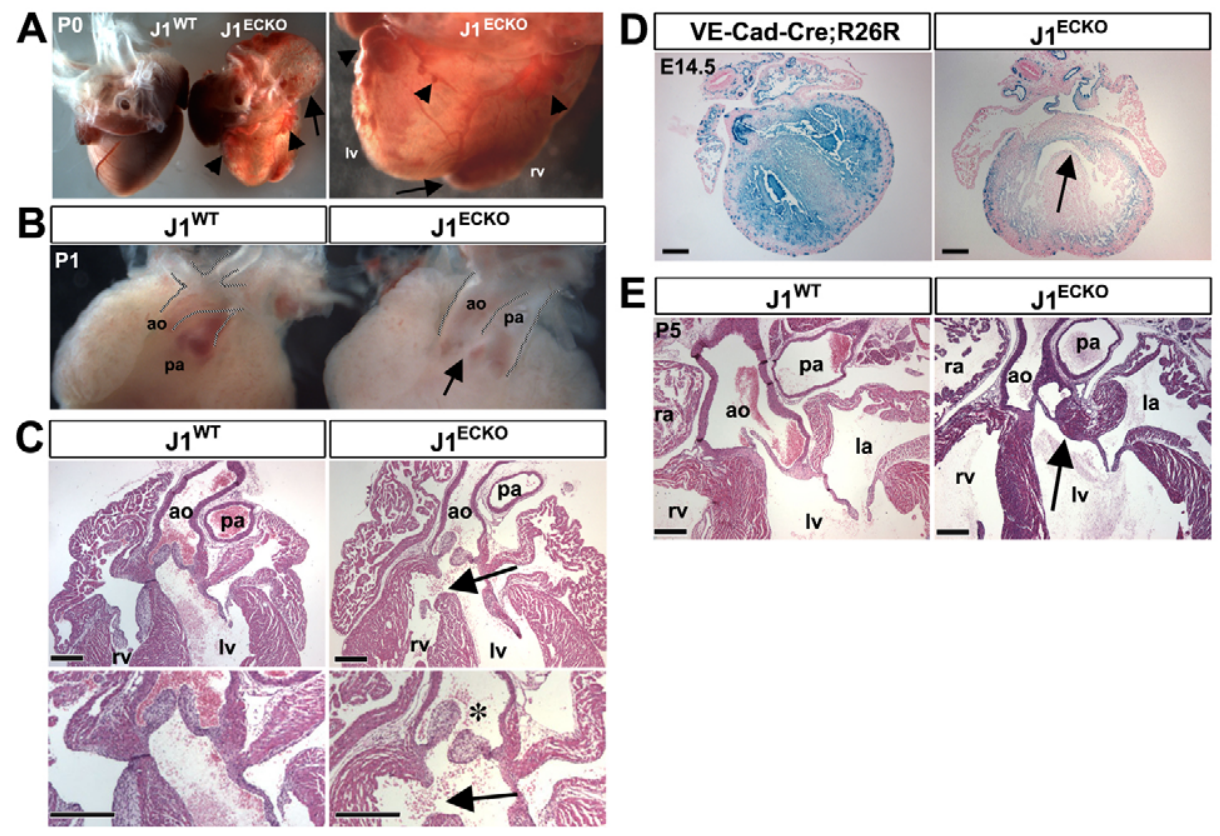

Fig. 3. AGS-related cardiac defects in embryonic and neonatal J1 ${ }^{\text {ECKO }}$ mice. (A-C) Light microscopy of the back $(A)$ and front (B) of neonatal $\mathrm{J} 1^{\mathrm{WT}}$ and $\mathrm{J} 1^{\mathrm{ECKO}}$ hearts $(n \geq 20)$. (A) Compared with J1 ${ }^{\mathrm{WT}}$ mice, hearts of PO J1 ECKO mice displayed a variety of cardiac defects, such as abnormal morphology and increased atrial and ventricular size (A, arrows), in addition to dilated, hemorrhaging cardiac vessels (A, arrowheads). (B) P1 hearts of $\mathrm{J} 1^{\mathrm{WT}}$ and $\mathrm{J} 1{ }^{\mathrm{ECKO}}$ mutants, with corresponding H\&E-stained histological sections of the respective hearts below (C). An overriding aorta was noted in the $\mathrm{J} 1{ }^{\mathrm{ECKO}}$ heart $(\mathrm{B}$, arrow). Dotted lines delineate great vessels and highlight outflow tract defects. (C) Histological sections of these J1 $\mathrm{ECKO}$ hearts, with high magnification images below, revealed ventricular septal defects (arrows) and hypertrophic valves (asterisk). (D) Light microscopy of $\beta$-galactosidase-stained histological sections of E14.5 VE-Cadherin-Cre; Rosa26R wild-type and J1ECKO hearts revealed VSDs in the mutant hearts (D, arrow) 24 hours after the septum normally closes, as seen in the wild-type heart (D). (E) Large bulges were occasionally found near the valve annulus between the left atria and ventricle in P5 J1ECKO H\&E-stained hearts (E, arrow). ao, aorta; la, left atrium; lv, left ventricle; pa, pulmonary artery; ra, right atrium; rv, right ventricle. Scale bars: $200 \mu \mathrm{m}$. 

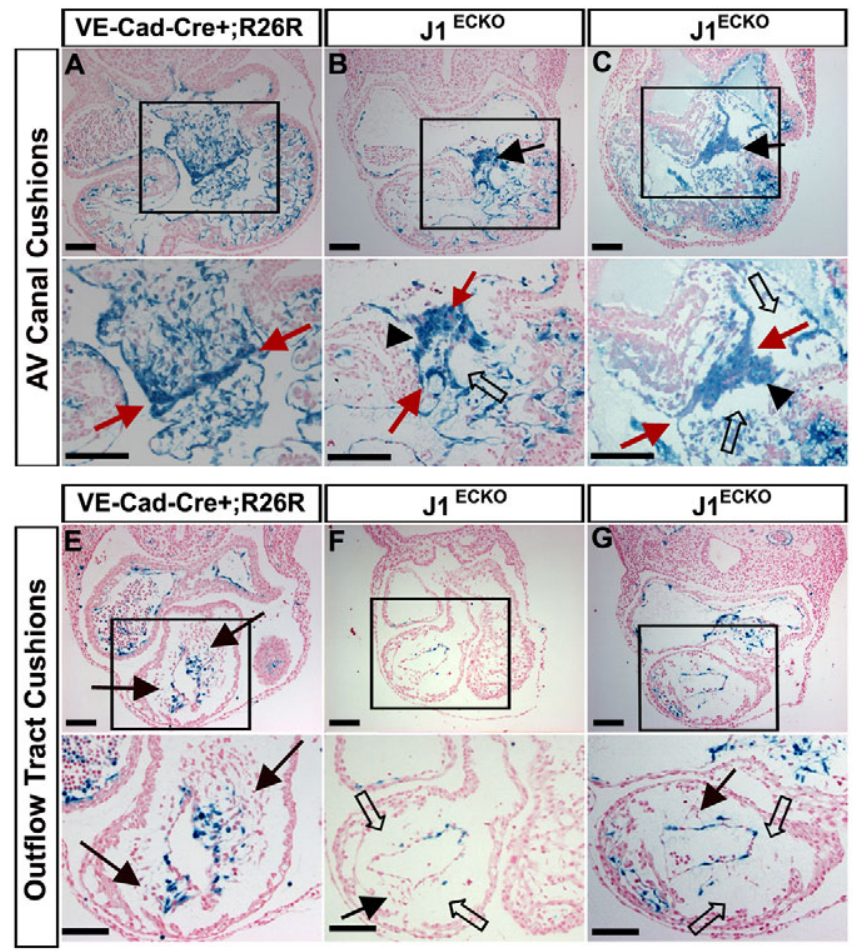

transformed mesenchymal cells (Fig. 4D, open arrows). Similar to the AV cushions, the OFT or semilunar cushions, which form the aortic and pulmonary valves, also showed delayed EndMT in both the $\mathrm{J}^{\mathrm{ECKO}}$ and $\mathrm{N} 1^{\mathrm{ECKO}}$ mice (Fig. 4E-H). Some $\beta$-galactosidasenegative mesenchymal cells were present in the cardiac jelly of $\mathrm{J}^{\mathrm{ECKO}}$ mice, demonstrating that EndMT was able to occur in areas without VE-Cadherin-Cre expression (Fig. 4F,G, arrows). However, in regions in which endocardial cells were $\beta$ galactosidase positive, EndMT was disrupted (Fig. 4F-H, open arrows). As mentioned previously, the survival of the $\mathrm{J} 1{ }^{\mathrm{ECKO}}$ mice and the wide range in phenotypes can be explained by the slow penetration of VE-Cadherin-Cre recombination at crucial times during EndMT (Fig. 1B).

\section{J1ECKO hearts demonstrate impaired EndMT in vitro due to a loss of Notch signaling}

To investigate the cellular events associated with the loss of Jag1, we explanted cardiac cushions from the AV canal of E9.5 $\mathrm{J}{ }^{\mathrm{ECKO}}$ mice for 48-72 hours and evaluated EndMT as previously described (Eisenberg and Markwald, 1995; Lakkis and Epstein, 1998). AV explants from $\mathrm{J} 1{ }^{\mathrm{WT}}$ mice had outgrowths of elongated $\alpha \mathrm{SMA}$ (Acta2 - Mouse Genome Informatics)-positive cells that invaded the collagen gel, indicative of endocardial cells transforming into mesenchymal cells (Fig. 5A, arrows). Loss of Jag1 in the endothelium resulted in a persistence of Pecam1-positive endocardial cells (Fig. 5A, arrowheads) and $\alpha$ SMA-negative cells (untransformed) that grew out of the explant, but remained on the surface of the collagen gel as a sheet (Fig. 5A, bracket). Less than half of $\mathrm{J} 1{ }^{\mathrm{ECKO}}$ endocardial cells were transformed (Fig. 5B). Thus, the loss of only endothelial Jagl resembled blockade of all Notch reporter signaling via the $\gamma$-secretase inhibitor $N$-[N-(3,5difluorophenacetyl)-L-alanyl]-S-phenylglycine t-butyl ester (DAPT) in wild-type cushions (Fig. 5A,C) (Timmerman et al., 2004). EndMT disruption was noted in all explants from $\mathrm{J} 1^{\mathrm{ECKO}}$ embryos (7/7 mice), indicating a crucial role for endothelial Jag1 early in this process.

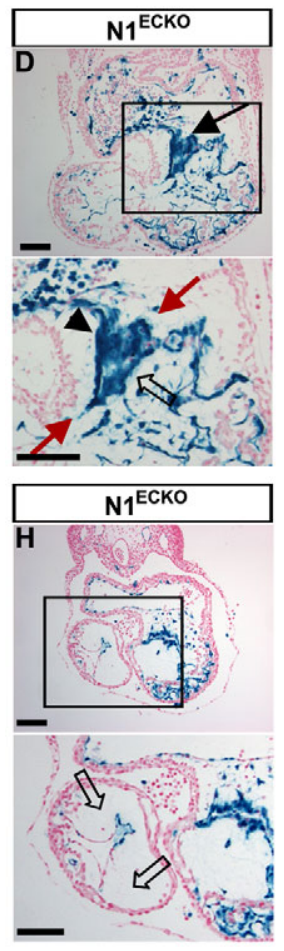

Fig. 4. Loss of Notch signaling impairs EndMT in cardiac and outflow cushions.

(A-H) $\beta$-Galactosidase- and Nuclear Fast Redstained sections of E10.5 control $(A, E), J 1 E C K O$ $(\mathrm{B}, \mathrm{C}, \mathrm{F}, \mathrm{G})$, and $\mathrm{N} 1{ }^{\mathrm{ECKO}}(\mathrm{D}, \mathrm{H})$ mouse hearts ( $n=4$ or more samples evaluated per cohort). Loss of endothelial Jag1 $(B, C)$ leads to delayed EMT in E10.5 cardiac cushions (magnified view indicated by box) compared with control (A). Defects in $\mathrm{N} 1{ }^{\mathrm{ECKO}}$ hearts (D) phenocopy those of the $\mathrm{J} 1 \mathrm{ECKO}$ hearts $(B, C)$. Rounded cells (arrowheads) were attached to the cushion interface (red arrows), and both $\mathrm{N} 1{ }^{\mathrm{ECKO}}$ and $\mathrm{J} 1{ }^{\mathrm{ECKO}}$ hearts displayed areas of decreased cellular density within the cardiac jelly (B-D, open arrows) compared with control (A). (E-H) The OFT cushions of E10.5 $\mathrm{J}_{1} \mathrm{ECKO}$ and $\mathrm{N} 1{ }^{\mathrm{ECKO}}$ mutants were also hypocellular ( $\mathrm{F}-\mathrm{H}$, open arrows) in contrast to extensive EndMT observed in control littermates (E, black arrows) (magnified view indicated by box). Mesenchymal cells were transformed in J1ECKO mutant OFT cushions mostly in places with unrecombined endothelium, revealed by absence of $\beta$-galactosidase staining ( $F, G$, black arrows). Scale bars: $100 \mu \mathrm{m}$.
Jag1 can function as an antagonistic ligand to Delta-like 4 (Dl14) in the endothelium (Benedito et al., 2009). Thus, it was important to understand whether absence of Jagl in the endocardium resulted in blockade or activation of Notch signaling. Using a Notch GFP reporter mouse line crossed to the $\mathrm{J}{ }^{\mathrm{ECKO}}$ mice, we found that removal of Jagl in the endothelium led to a loss of Notch signaling in the endocardial cushion interface and within transformed mesenchymal cells (Fig. 5D). J1 ${ }^{\mathrm{ECKO}}$ endocardial cells $\left(\mathrm{GFP}^{-}\right.$), retained Pecam1 expression and were stacked several layers thick, whereas the cardiac jelly remained less densely populated (Fig. 5D, open arrow). By contrast, Notch reporter expression in vessels of $\mathrm{J} 1^{\mathrm{ECKO}}$ mice remained similar to littermate controls (Fig. 5E, arrows). This indicates that the cardiac endothelium of $\mathrm{J} 1{ }^{\mathrm{ECKO}}$ mice display a loss-of-function phenotype, whereas other endothelial populations probably have compensation from additional Notch ligands, such as D114.

As the majority of $\mathrm{J}{ }^{\mathrm{ECKO}}$ mice survive to adulthood, it suggests an eventual compensation for the loss of Jagl, a modifier effect from the genetic background, or incomplete deletion when EndMT is occurring. However, this fortuitous feature resembles the phenotype of the cardiac defects in human AGS disease and provides a broader picture of the multiple effects of Jag1 at later stages of cardiovascular development.

\section{Jag1 is required for valve morphogenesis}

The cardiac cushion defects present in $\mathrm{J}^{\mathrm{ECKO}}$ and $\mathrm{N} 1^{\mathrm{ECKO}}$ hearts, as well as the link to calcific aortic valve disease in humans and animal models, prompted a more detailed evaluation of the valves in surviving J1 ${ }^{\mathrm{ECKO}}$ mice (Acharya et al., 2011; Garg et al., 2005; Nigam and Srivastava, 2009). As valve leaflets mature, they initially swell up and are composed of layers of extracellular matrix proteins, which are then remodeled and form tapered and thin structures (Hinton and Yutzey, 2011). However, valves of $\mathrm{J}^{\mathrm{ECKO}}$ hearts exhibited defective remodeling, as they remained myxomatous, or club-shaped (Fig. 3; Fig. 6). 

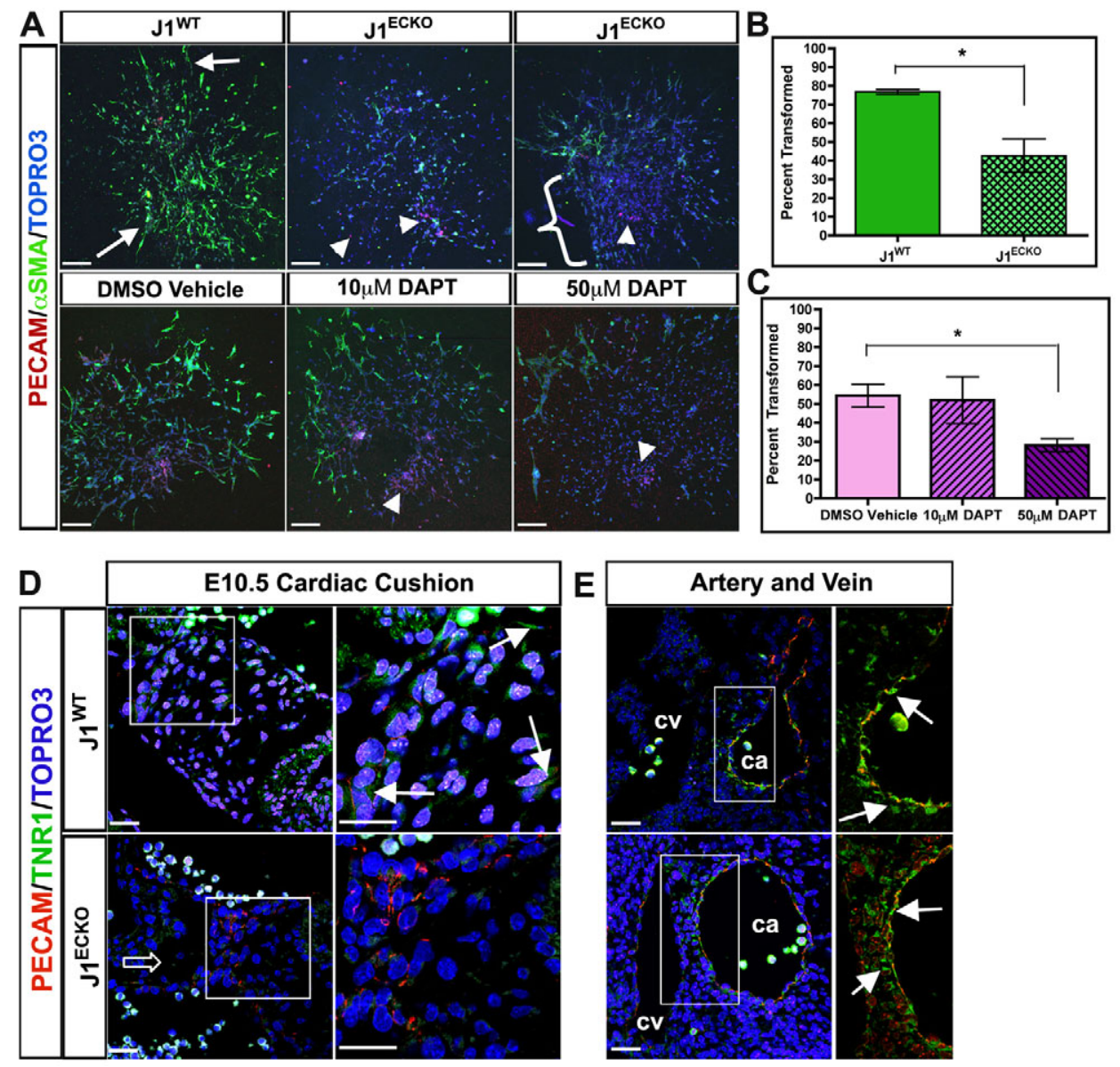

Fig. 5. Jag1 is a crucial ligand for Notch signaling during EndMT in endocardial cushions. (A) Representative images of E9.5 cardiac cushion explants cultured for 48 hours, fixed, stained with anti- $\alpha$ SMA (in green, arrows) and anti-PECAM1 (in red, arrowheads). Explants from J1 ECKO hearts showed a reduction in the number of transformed, $\alpha S M A^{+}$cells compared with controls ( $A$, top panel), and exhibited sheets of Pecam $1^{+}$ endothelial cells (A, arrowheads) on gel surface (A, bracket). (B) Quantification of transformed cells (calculated by $\alpha$ SMA ${ }^{+}$cells/total nuclei) obtained from J1 $1^{\mathrm{WT}}$ and $\mathrm{J} 1 \mathrm{ECKO}$ explants. Bars represent the mean \pm s.e.m. The percentage of transformed cells was significantly reduced in J1 1 ECKO explants $\left({ }^{*} P=0.012\right)$ compared with J1 ${ }^{\mathrm{WT}}$ explants $(P<0.05)$. Blocking Notch signaling in wild-type E9.5 explants with the $\gamma$-secretase inhibitor DAPT mimicked the $\mathrm{J} 1{ }^{\mathrm{ECKO}}$ phenotype with a dose-dependent reduction of transformed cells (arrowheads in A, lower panels). (C) Quantification of transformed cells from explants exposed to either vehicle (DMSO) or DAPT for 48 hours after isolation from E9.5 wild-type embryos. Bars represent the mean \pm s.e.m. Although the $P$-value of 0.09 did not reach significance by one-way ANOVA owing to increased variance in the $10 \mu M$ DAPTtreated group, application of the Bonferroni correction with an adjusted $P$-value $(P=0.0167)$ to the pairwise $t$-test showed a significant difference between the $50 \mu \mathrm{M}$ DAPT-treated group ( ${ }^{*} P=0.009$ ) and DMSO vehicle-only control. For AV explants for each group, $n=4-5$ from different litters of 20- to 28-somite embryos. (D) Evaluation of Notch signaling in J1WT and J1ECKO hearts using GFP reporter from TNR 1 transgenic crosses. Cardiac cushions at E10.5 showed prominent Notch activity (green) in J1 ${ }^{\mathrm{WT}}$ mice (arrows) and low levels of Pecam1 (red). By contrast, cushions from J1 ECKO exhibited high levels of Pecam1 (red) and a conspicuous absence of Notch reporter (green). (E) When the carotid artery (ca) and cardinal vein (cv) from the same animals were evaluated, no significant differences in Notch reporter levels/location (green) were noted between J1 ${ }^{\mathrm{WT}}$ and $\mathrm{J} 1{ }^{\mathrm{ECKO}}$ mice. Scale bars: $150 \mu \mathrm{m}$ in $\mathrm{A} ; 25 \mu \mathrm{m}$ in $\mathrm{D}, \mathrm{E}$.

To investigate the mechanism behind the abnormal valve thickening in $\mathrm{J}^{\mathrm{ECKO}}$ hearts, we first determined whether there were differences in cell number (Fig. 6C,D). In neonatal animals (P0), no significant changes in the number of cells were found in $\mathrm{J}_{1}{ }^{\mathrm{ECKO}}$ valve leaflets compared with $\mathrm{J} 1{ }^{\mathrm{WT}}$. By P10, a point at which the valve thickening was more pronounced in $\mathrm{J} 1^{\mathrm{ECKO}}$ mice, nuclear density was lower in $\mathrm{J}^{\mathrm{ECKO}}$ compared with $\mathrm{J} 1^{\mathrm{WT}}$ valves (Fig. $6 \mathrm{C}$ ). We found decreased cellularity in the central region of the valve leaflet (spongiosa) in $\mathrm{P} 10 \mathrm{~J} 1^{\mathrm{ECKO}}$ animals (Fig. 6D). These data suggested that the thickening of heart valves in $\mathrm{J} 1^{\mathrm{ECKO}}$ animals is likely to be due to changes in the extracellular matrix (ECM), rather than in cell density.

The composition, stoichiometry and organization of ECM proteins are essential for heart valve morphogenesis and function
(Armstrong and Bischoff, 2004). As the spongiosa zone of the valves is rich in versican (Kern et al., 2006; Yamamura et al., 1997), we performed immunodetection analysis of the GAG $\beta$ isoform on heart cross-sections at P10. In all animals examined, versican levels, indicated by a pseudocolor scale, were increased in the valve leaflet of $\mathrm{J} 1^{\mathrm{ECKO}}$ mice compared with $\mathrm{J} 1^{\mathrm{WT}}$ animals (Fig. 7A).

To elucidate further the molecular events accounting for the increase in versican in $\mathrm{J} 1^{\mathrm{ECKO}}$ mice, we evaluated transcript expression profiles of OFT and AV valves at P10 (Fig. 7). As expected, Jag1 expression was decreased in both OFT and AV valve leaflets in $\mathrm{J}^{\mathrm{ECKO}}$ animals (by $\sim 70 \%$ ). By contrast, Notch1 and Dll4 were equivalent in $\mathrm{J}^{\mathrm{ECKO}}$ and $\mathrm{J} 1^{\mathrm{WT}}$ (Fig. 7B). Interestingly, mRNA expression of relevant versican isoforms 

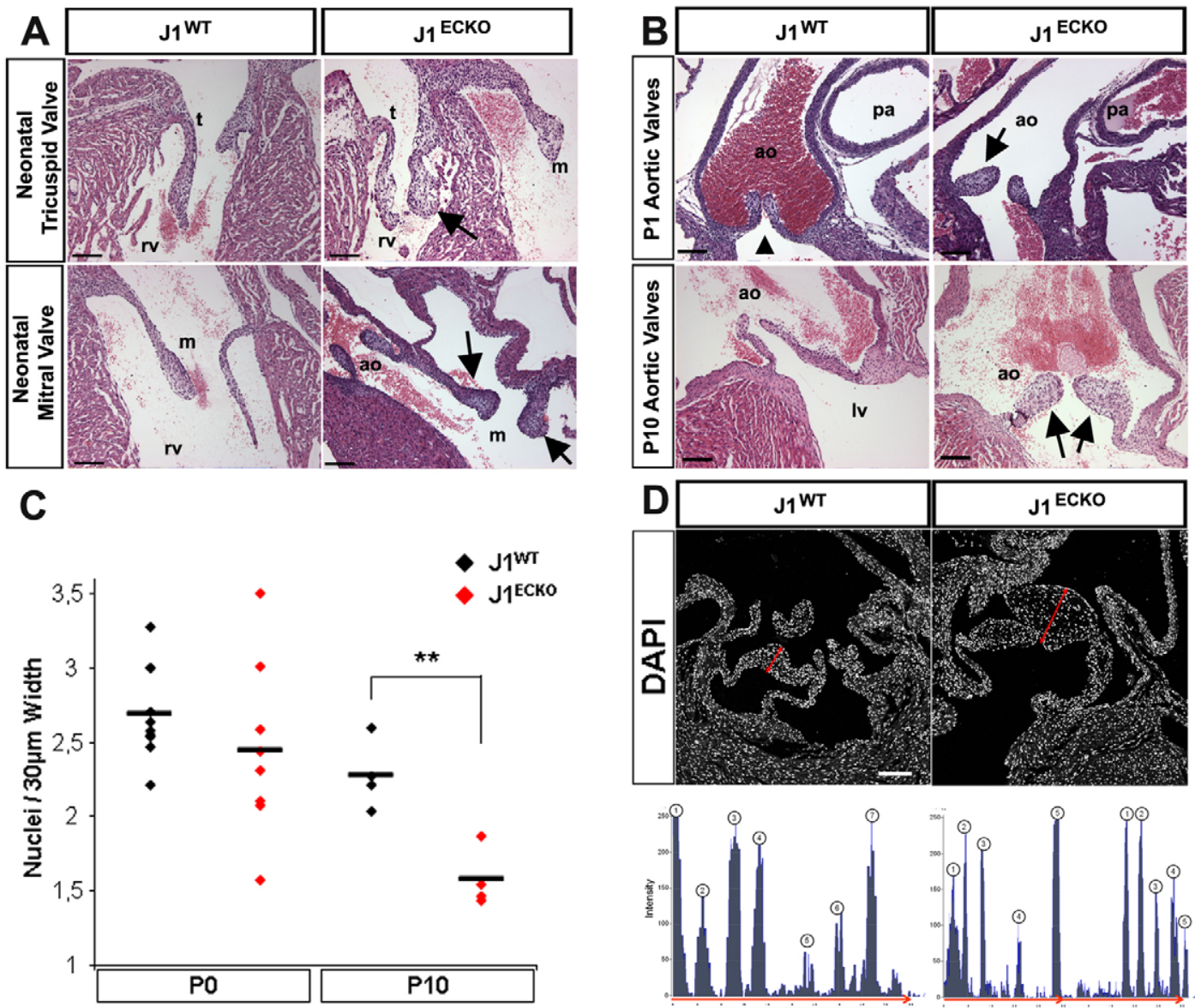

Fig. 6. Cardiac valve abnormalities in J1 ${ }^{\mathrm{ECKO}}$ animals. (A,B) H\&E-stained cardiac valves from J1 WT and J1 ${ }^{\mathrm{ECKO}}$ neonates. (A) The AV valves (tricuspid and mitral) of neonatal J1 ${ }^{E C K O}$ mice display a lack of remodeling and thickened valves compared with littermate controls (A, arrows). (B) Aortic valves of $\mathrm{P} 1 \mathrm{~J} 1{ }^{\mathrm{WT}}$ hearts are functionally compliant, keeping blood from returning to the lower compartment $(B$, arrowhead), in contrast to thickened valves from $\mathrm{J} 1 \mathrm{ECKO}^{\mathrm{ECO}}$ mice ( $\mathrm{B}$, arrow). Inadequate valve remodeling is evident in $\mathrm{J} 1 \mathrm{ECKO}$ hearts in the P10 aortic valves (B, arrows). (C) Nuclear density of valves from J1 1 WT and J1ECKO PO and P10 neonates. No difference in the number of nuclei was observed in J1 ${ }^{\mathrm{WT}}(n=10)$ and J1 ${ }^{\mathrm{ECKO}}(n=8)$ neonates; however, nuclear density appeared decreased in $\mathrm{J} 1 \mathrm{ECKO}$ valves $(n=4)$ compared with $\mathrm{J} 1^{\mathrm{WT}}(n=4)$ by P10. Horizontal bars represent the mean. (D) DAPI staining of cardiac valves at P10. The graphs below correspond to pixels intensity counts (maximum 250) performed by Zen software. Each peak in the graph represents a single nucleus. Seven nuclei are detected in J1WT valve width $(100 \mu \mathrm{m}$, one red arrow beneath graph). The larger valves of $\mathrm{J} 1 \mathrm{ECKO}$ mice showed similar cellular density, in this case ten nuclei in a $200 \mu \mathrm{m}$ thick valve (two red arrows beneath graph). ${ }^{*} P<0.01$. ao, aortic valve; Iv, left ventricle; $\mathrm{m}$, mitral; pa, pulmonary artery; rv, right ventricle; t, tricuspid. Scale bars: $100 \mu \mathrm{m}$.

$(V 0 / V 2$ and $V 1)$ revealed no significant variability in levels associated with Jagl deletion (Fig. 7C). This observation indicates that increased versican in $\mathrm{J} 1{ }^{\mathrm{ECKO}}$ valves cannot be accounted for by overexpression of the proteoglycan. We then focused on alterations in post-translational processing of versican by evaluating relevant proteases and their inhibitors. The metalloproteases Adamts1 and Adamts9 are known to cleave versican physiologically, and Timp3 inhibits both proteases (Rodríguez-Manzaneque et al., 2002; Sandy et al., 2001). All three molecules are expressed in the heart at the pertinent time points (Kern et al., 2007; Thai and Iruela-Arispe, 2002). In $\mathrm{J}^{\mathrm{ECKO}}$ mice, Timp3 showed a consistent, yet low increase in expression compared with $\mathrm{J} 1{ }^{\mathrm{WT}}$. Adamts 1 was not statistically different between mutant and controls. By contrast, Adamts 9 expression was significantly reduced in both OFT and AV valves of ${ }^{\mathrm{ECKO}}$ mice (Fig. 7D). Thus, it appears that the accumulation of versican in $\mathrm{J} 1{ }^{\mathrm{ECKO}}$ valves is likely to be due to limited versican turnover and deficient valve remodeling.
To confirm these findings, we performed immunostaining of valves with antibodies that recognize a neoepitope sequence of versican (DPEAAE) generated after cleavage by matrix metalloproteases, including Adamts (Sandy et al., 2001; Somerville et al., 2003). Cleaved versican in $\mathrm{J}^{\mathrm{WT}}$ valves was weak, but was detected throughout the leaflet. By contrast, processed versican was mainly noted in the peripheral areas of $\mathrm{J}^{\mathrm{ECKO}}$ valves (Fig. 7E). Thus, Jagl deletion in the endothelium results in decreased Adamts 9 and defects in versican degradation, leading to arrested valve remodeling and myxomatous valves.

\section{Cartilage nodules and calcification in adult J1ECKO valves}

Given that sudden lethality was observed in adult $\mathrm{J} 1^{\mathrm{ECKO}}$ mice and that Notch1 mutations are linked to aortic valve calcification (Garg et al., 2005), we further examined valves in mutant and control littermates at several adult stages (5-13 months). Histological analysis revealed increased OFT valve leaflet width (Fig. 8A, bracket). 

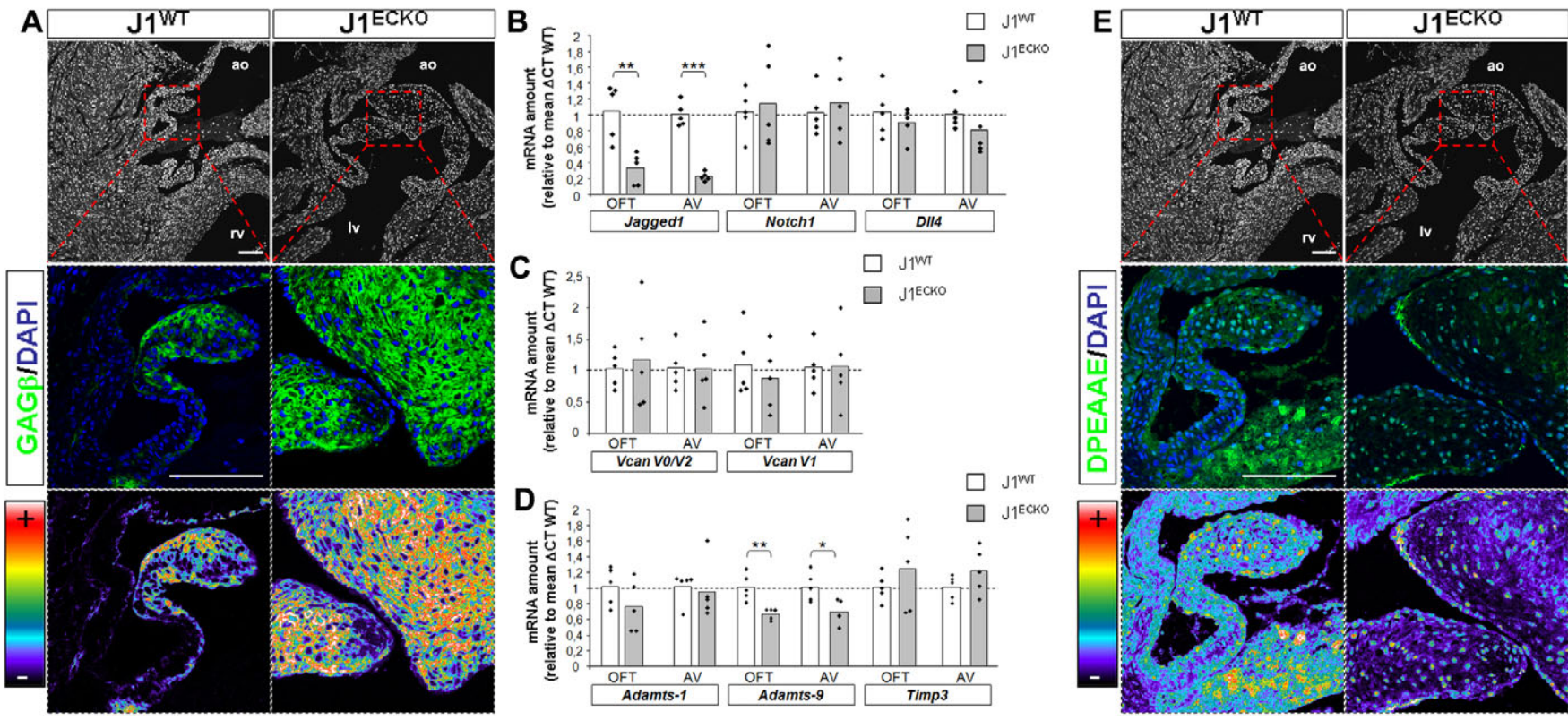

Fig. 7. Valve thickening in $\mathrm{J1}^{\mathrm{ECKO}}$ animals is associated with increased versican deposition and decreased versican cleavage. (A) Versican GAG $\beta$ immunodetection (green) of valves from P10 mice is present throughout the $\mathrm{J}_{1}^{\mathrm{ECKO}}$ valve leaflet whereas it is mainly near the periphery of the $\mathrm{J} 1^{\mathrm{WT}}$ leaflet. A pseudocolor scale used for GAG $\beta$ detection revealed increased staining intensity in $\mathrm{J}^{\mathrm{ECKO}}$ valves, as illustrated by the increase of warm range pixels (orange to white), compared with $\mathrm{J} 1^{\mathrm{WT}}$. (B-D) qPCR analysis of OFT and AV valves mRNA at P10. mRNA levels were normalized using Hprt as a housekeeping gene. The data are expressed relative to mean $\Delta C T$ of control animals (J1WT $n=5$; J1 ${ }^{\mathrm{ECKO}} n=5$ ). (B) Notch signaling pathway-related genes. Jagged $1 \mathrm{mRNA}$ is significantly decreased in J1ECKO OFT and AV valves compared with J1 ${ }^{\mathrm{WT}}$, whereas Notch1 and DII4 do not vary. (C) Versican isoforms (VO/V2 and V1) mRNA expression showed no change when comparing valves from J1 ${ }^{W T}$ and J1 ECKO mice. (D) Expression of versican-processing proteases and inhibitors. Only minor changes were detected in Adamts1 expression, whereas Adamts9 expression was significantly decreased in both $\mathrm{J}_{1} \mathrm{ECKO}$ OFT and AV valves. Although not statistically significant, the inhibitor Timp3 was increased in the J1ECKO valves. (E) Versican neoepitope DPEAAE immunodetection of P10 valves. Immunostaining intensity was lower in J1 ${ }^{\mathrm{ECKO}}$ valves Compared with $\mathrm{J1}{ }^{\mathrm{WT}}$ ${ }^{*} P<0.02,{ }^{*} P<0.01, * * * P<0.001$. Scale bars: $100 \mu \mathrm{m}$.

Interestingly, we also detected the presence of cartilage nodules (red arrowheads) and bone (black arrowheads) in the annulus (Fig. 8A, dotted circle) and/or in the body of aortic valve leaflets (Fig. 8A). Even though the animals exhibited no outward signs of disease, we found a $50 \%$ frequency $\left(5 / 10 \mathrm{~J} 1{ }^{\mathrm{ECKO}}\right.$ mice, $0 / 10$ controls $)$ of chondrogenic nodules or bone tissue in $\mathrm{J}{ }^{\mathrm{ECKO}}$ animals, whereas no such abnormalities were noted in Cre-negative littermates. Von Kossa and Alizarin Red staining of heart sections confirmed bone dysplasia and high levels of calcium deposition in the valves of adult $\mathrm{J} 1{ }^{\mathrm{ECKO}}$ animals (Fig. 8B, black arrowhead; supplementary material Fig. S1). Calcium deposits were more evident in the annulus, rather than in the leaflet of the valves (Fig. 8B).

To determine the cellular origin of the abnormal tissue, we performed lineage analysis of $\mathrm{VE}$-Cad-Cre;R26R animals. Although it is well accepted that valve fibroblasts originate from the endothelium, lineage analysis in older adult mice has not been performed. Both the annulus and valve leaflets were largely positive for Cre activity, denoted by $\beta$-galactosidase staining (Fig. $8 \mathrm{C}$, red arrows). Thus, the majority of cells located in both the leaflets and the annulus are derived from an endothelial progenitor and in $\mathrm{J} 1^{\mathrm{ECKO}}$ mice are, therefore, Jag 1 deficient. These data strongly support that, in addition to its role in early heart development, Jag1 signaling is required postnatally to prevent valve calcification (Fig. 9)

\section{DISCUSSION}

The results of this study demonstrate a crucial role for Jag1 in the endocardium during heart development and provide a new clinically relevant model for the human cardiac phenotypes associated with AGS and valve disease. Loss of Jag1 or Notch1 in the endothelium using VE-Cadherin-Cre, led to disruption of EndMT in the AV canal and OFT cushions. In addition, $50 \%$ of the mutants that survived to adulthood exhibited valve defects and calcification. Together, these data indicate that endothelial Jag1 affects distinct temporal stages of heart development through diverse and non-overlapping mechanisms.

The inherent complexity of a multisystem syndrome such as AGS makes the identification of the cells responsible and the treatment of the disease problematic. Other endothelial-specific Jag1 knockout mice succumb to lethality by E10.5, similar to global inactivation of Jagl (Benedito et al., 2009; High et al., 2008; Xue et al., 1999). Although these endothelial cell Jagl-deficient mice demonstrated pericardial edema and defects in smooth muscle cell recruitment, major cardiac defects, such as those associated with AGS, were not found in those models owing to the early lethality (Nemir and Pedrazzini, 2008). Although much has been done to develop a mouse model that faithfully reproduces AGS, introduction of the human mutations in mice do not yield the clinical features of AGS. Specifically, mice with loss of heterozygosity or harboring missense mutations of Jagl exhibit only a few characteristics of AGS with very mild severity or weak penetration (Vrijens et al., 2006; Xue et al., 1999). Only doubly heterozygous Jag1;Notch2 mice reconstitute a more human-like AGS model that shows both major hepatic and cardiac defects (McCright et al., 2002). As a result of its later deletion, the $\mathrm{J} 1{ }^{\mathrm{ECKO}}$ model presented here recapitulates, exclusively, many of the 

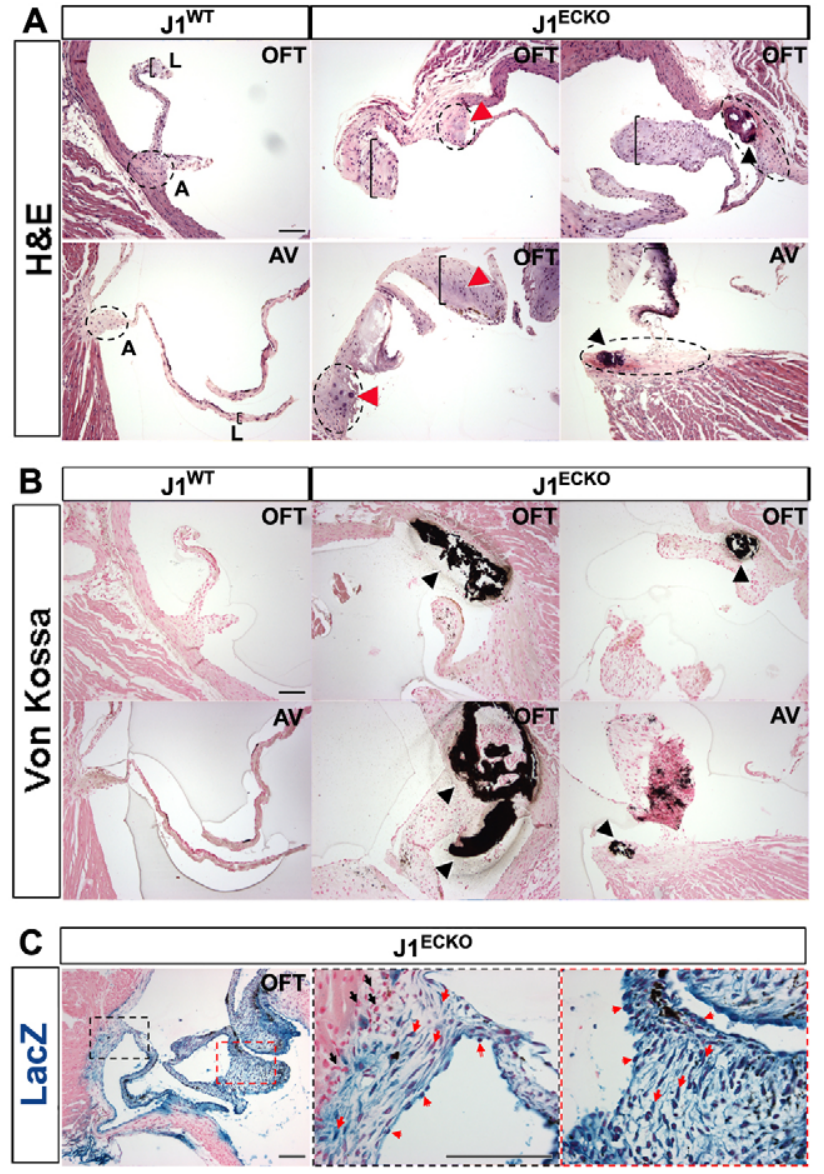

Fig. 8. Jagged 1 deletion in endothelial cells is associated with calcification of adult heart valves. $(\mathbf{A}, \mathbf{B}) \mathrm{J} 1^{\mathrm{WT}}$ and $\mathrm{J} 1^{\mathrm{ECKO}}$ mice between 5 and 13 months old were randomly selected $\left(\mathrm{J} 1^{\mathrm{WT}} n=10\right.$; $\mathrm{J1}^{\mathrm{ECKO}} n=10$ ). (A) H\&E staining of valves showed cartilage-like nodules ( $A$, red arrowhead) and bone tissue (A, black arrowhead) in OFT and AV valves of $\mathrm{J1}{ }^{\mathrm{ECKO}}$ adult mice. These features were absent from valves of $\mathrm{J} 1{ }^{\mathrm{WT}}$ mice. Also, note that OFT valve leaflets appeared thicker in $\mathrm{J} 1 \mathrm{ECKO}$ compared with $J 1^{\mathrm{WT}}$ animals (A, brackets). The annulus is shown as a dashed circle. (B) Von Kossa staining confirmed the presence of calcium accumulation in the bone-like tissue observed in $\mathrm{J1}{ }^{\mathrm{ECKO}}$ valves, particularly in the annulus region (black arrowheads). (C) $\beta$ Galactosidase staining of valves from adult VE-Cadherin-Cre;R26R animals (high magnification images indicated by black and red boxes) revealed Cre activity in both valve annulus and leaflets (red arrows), highlighting the endothelial origin of cells that populate these regions. $\beta$-Galactosidase-negative cells are noted by black arrows. OFT and J1WT $A V$ valve leaflets are shown from a three-leaflet view, whereas the $J 1^{E C K O} A V$ valve is a four-chamber view of the section. $A$, annulus; $L$, leaflet. Scale bars: $100 \mu \mathrm{m}$.

cardiac defects of AGS, avoiding potential complications caused by liver dysfunction. In fact, as an autosomal dominant disorder, the phenotype displayed in human AGS appears to be mimicked in mice by progressive loss of function when it is manifested after E10.5, a time when complete absence of Jag1 in the endothelium is lethal (High et al., 2008).

The observation of abnormal patterning, branching and fragility of the coronary vessels shown in neonatal and adult $\mathrm{J} 1{ }^{\mathrm{ECKO}}$ mice is novel and one not previously reported in other surviving Jag1 mutant mice (Benedito et al., 2009; McCright et al., 2002; Vrijens et al., 2006). As already mentioned, most Jagl knockout mice die
Contribution of Jagged1 to valve morphogenesis

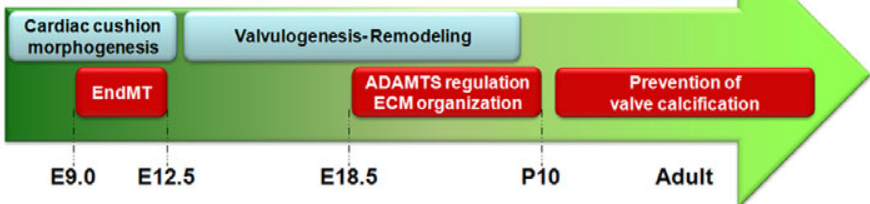

$\square$ Physiological Events

JAGGED1 key role

Fig. 9. Contribution of Jag1 to cardiac development. At midgestation (E9.5-14.5), Jag1 is crucial for EndMT with essential contributions to morphogenesis of the interventricular septum and $A V$, aortic and pulmonary valves. In addition, Jag1 regulates valve remodeling postnatally by affecting ECM dynamics and by preventing valve calcification.

before the coronary plexus starts forming at E11.5 (Benedito et al., 2009; High et al., 2008; Xue et al., 1999). Because the coronary vessels originate primarily from VE-Cadherin-positive endothelial sprouts of the sinus venosus, with a secondary source coming from the endocardium, and because Jagl is known to be expressed in both areas, our data suggest a role for Jag1 in the proper formation and integrity of the coronary vasculature (de la Pompa and Epstein, 2012; Penton et al., 2012; Red-Horse et al., 2010). The increased vessel branching demonstrated by $\mu \mathrm{CT}$ imaging was fairly unexpected and intriguing, as inducible loss of endothelial Jagl led to decreased branching in postnatal retinas (Benedito et al., 2009). Additionally, recent studies demonstrate a requirement of endothelial Jag1 for mural cell development and differentiation, which warrants a thorough examination of these vessels and their smooth muscle and pericyte coverage (High et al., 2008; Liu et al., 2009; Scheppke et al., 2012).

The contribution of the Notch receptor and its downstream targets to EndMt has long been acknowledged; however, the Notch ligand and the specific cell type responsible for these events had not been definitively identified (de la Pompa and Epstein, 2012). Although Dll4 mutants display mild EndMT defects in the outflow tract cushions (Trindade et al., 2008), the intensity and features displayed with the absence of Jag1 clearly indicate that this is the most relevant ligand in EndMT. Interestingly, Jag1 has been associated with EMT in multiple systems. For example, in cultured epithelial cells from normal tissues and breast cancer lines, as well as human microvascular endothelial cells, Jag1 has been implicated in the cascade of signaling required for EMT (Leong et al., 2007; Noseda et al., 2004; Zavadil et al., 2004). In the secondary heart field, Notch and Jag1 regulate $F g f 8$ expression in a non-cell-autonomous manner during OFT EndMT (High et al., 2009).

The present study also offers insights into the role of Jag1 in valve remodeling. Mutations in NOTCH1 have been previously associated with congenital aortic valve malformations and calcification (de la Pompa and Epstein, 2012; Garg et al., 2005; MacGrogan et al., 2011). In addition, there is accumulating evidence that Notch signaling inhibits aortic valve calcification (Acharya et al., 2011; Garg et al., 2005; Nigam and Srivastava, 2009). Nonetheless, the specific contribution of Notch signaling to valve organization and ECM remodeling was unclear. Our findings indicate that Jag1 is a crucial Notch ligand in valves and its 
inactivation results in a high incidence of valve calcification. Furthermore, we found an imbalance in versican cleavage that could be explained by reduced expression in Adamts9, the gene encoding a relevant protease for versican processing and turnover. Interestingly, mice heterozygous for Adamts 9 exhibit reduced versican cleavage, myxomatous valves, and development of cartilaginous valve nodules (Kern et al., 2010). The adequate balance of matrix proteins in valve remodeling is essential to its morphogenesis and function. Mice lacking a specific subset of ECM molecules succumb to lethality associated with valve disease (for a review, see Hinton and Yutzey, 2011).

The findings presented here indicate that, at least in the valves, Jag1 is an important regulator of ECM organization that is crucial for valve compliance. As determining the factors involved in congenital heart malformations and valve disease is of high clinical relevance, these findings should provide new avenues of investigation, while answering several long-standing questions about the role of Jag1 in heart development and disease.

\section{Acknowledgements}

The authors would like to acknowledge Liman Zhao, Huilin Koh and Michelle Steel for their technical assistance; and Dr Gerry Weinmaster (UCLA) for thoughtful discussions. We thank the UCLA Tissue Procurement Core Laboratory Shared Resource for histological processing.

\section{Funding}

This work was supported by the National Institutes of Health [RO1HL 085618]; the American Heart Association [AHA-0715053Y to J.J.H.]; and the Leducq Foundation. Deposited in PMC for release after 12 months.

Competing interests statement

The authors declare no competing financial interests.

\section{Supplementary material}

Supplementary material available online at

http://dev.biologists.org/lookup/suppl/doi:10.1242/dev.084871/-/DC1

\section{References}

Acharya, A., Hans, C. P., Koenig, S. N., Nichols, H. A., Galindo, C. L., Garner, H. R., Merrill, W. H., Hinton, R. B. and Garg, V. (2011). Inhibitory role of Notch1 in calcific aortic valve disease. PLoS ONE 6, e27743.

Alva, J. A., Zovein, A. C., Monvoisin, A., Murphy, T., Salazar, A., Harvey, N. L., Carmeliet, P. and Iruela-Arispe, M. L. (2006). VE-Cadherin-Crerecombinase transgenic mouse: a tool for lineage analysis and gene deletion in endothelial cells. Dev. Dyn. 235, 759-767.

Armstrong, E. J. and Bischoff, J. (2004). Heart valve development: endothelial cell signaling and differentiation. Circ. Res. 95, 459-470.

Bauer, R. C., Laney, A. O., Smith, R., Gerfen, J., Morrissette, J. J., Woyciechowski, S., Garbarini, J., Loomes, K. M., Krantz, I. D., Urban, Z. et al. (2010). Jagged1 (JAG1) mutations in patients with tetralogy of Fallot or pulmonic stenosis. Hum. Mutat. 31, 594-601.

Benedito, R., Roca, C., Sörensen, I., Adams, S., Gossler, A., Fruttiger, M. and Adams, R. H. (2009). The notch ligands DII4 and Jagged1 have opposing effects on angiogenesis. Cell 137, 1124-1135.

Camenisch, T. D., Molin, D. G., Person, A., Runyan, R. B., Gittenberger-de

Groot, A. C., McDonald, J. A. and Klewer, S. E. (2002). Temporal and distinct TGFbeta ligand requirements during mouse and avian endocardial cushion morphogenesis. Dev. Biol. 248, 170-181.

Chen, T. T., Luque, A., Lee, S., Anderson, S. M., Segura, T. and Iruela-Arispe, M. L. (2010). Anchorage of VEGF to the extracellular matrix conveys differential signaling responses to endothelial cells. J. Cell Biol. 188, 595-609.

Crosnier, C., Attié-Bitach, T., Encha-Razavi, F., Audollent, S., Soudy, F., Hadchouel, M., Meunier-Rotival, M. and Vekemans, M. (2000). JAGGED1 gene expression during human embryogenesis elucidates the wide phenotypic spectrum of Alagille syndrome. Hepatology 32, 574-581.

de la Pompa, J. L. and Epstein, J. A. (2012). Coordinating tissue interactions: Notch signaling in cardiac development and disease. Dev. Cell 22, 244-254.

Duncan, A. W., Rattis, F. M., DiMascio, L. N., Congdon, K. L., Pazianos, G., Zhao, C., Yoon, K., Cook, J. M., Willert, K., Gaiano, N. et al. (2005). Integration of Notch and Wnt signaling in hematopoietic stem cell maintenance. Nat. Immunol. 6, 314-322

Eisenberg, L. M. and Markwald, R. R. (1995). Molecular regulation of atrioventricular valvuloseptal morphogenesis. Circ. Res. 77, 1-6.
Eldadah, Z. A., Hamosh, A., Biery, N. J., Montgomery, R. A., Duke, M., Elkins, R. and Dietz, H. C. (2001). Familial Tetralogy of Fallot caused by mutation in the jagged1 gene. Hum. Mol. Genet. 10, 163-169.

Feng, X., Krebs, L. T. and Gridley, T. (2010). Patent ductus arteriosus in mice with smooth muscle-specific Jag1 deletion. Development 137, 4191-4199.

Fischer, A., Steidl, C., Wagner, T. U., Lang, E., Jakob, P. M., Friedl, P., Knobeloch, K. P. and Gessler, M. (2007). Combined loss of Hey1 and HeyL causes congenital heart defects because of impaired epithelial to mesenchymal transition. Circ. Res. 100, 856-863.

Garg, V., Muth, A. N., Ransom, J. F., Schluterman, M. K., Barnes, R., King, I. N., Grossfeld, P. D. and Srivastava, D. (2005). Mutations in NOTCH1 cause aortic valve disease. Nature 437, 270-274.

Gridley, T. (2010). Notch signaling in the vasculature. Curr. Top. Dev. Biol. 92, $277-$ 309.

High, F. A. and Epstein, J. A. (2008). The multifaceted role of Notch in cardiac development and disease. Nat. Rev. Genet. 9, 49-61.

High, F. A., Lu, M. M., Pear, W. S., Loomes, K. M., Kaestner, K. H. and Epstein, J. A. (2008). Endothelial expression of the Notch ligand Jagged1 is required for vascular smooth muscle development. Proc. Natl. Acad. Sci. USA 105, 1955-1959

High, F. A., Jain, R., Stoller, J. Z., Antonucci, N. B., Lu, M. M., Loomes, K. M., Kaestner, K. H., Pear, W. S. and Epstein, J. A. (2009). Murine Jagged1/Notch signaling in the second heart field orchestrates Fgf8 expression and tissue-tissue interactions during outflow tract development. J. Clin. Invest. 119, 1986-1996.

Hinton, R. B. and Yutzey, K. E. (2011). Heart valve structure and function in development and disease. Annu. Rev. Physiol. 73, 29-46.

Hofmann, J. J., Zovein, A. C., Koh, H., Radtke, F., Weinmaster, G. and IruelaArispe, M. L. (2010). Jagged1 in the portal vein mesenchyme regulates intrahepatic bile duct development: insights into Alagille syndrome. Development 137, 4061-4072

Jones, E. A., Clement-Jones, M. and Wilson, D. I. (2000). JAGGED1 expression in human embryos: correlation with the Alagille syndrome phenotype. J. Med. Genet. 37, 658-662.

Kern, C. B., Twal, W. O., Mjaatvedt, C. H., Fairey, S. E., Toole, B. P., IruelaArispe, M. L. and Argraves, W. S. (2006). Proteolytic cleavage of versican during cardiac cushion morphogenesis. Dev. Dyn. 235, 2238-2247.

Kern, C. B., Norris, R. A., Thompson, R. P., Argraves, W. S., Fairey, S. E., Reyes, L., Hoffman, S., Markwald, R. R. and Mjaatvedt, C. H. (2007). Versican proteolysis mediates myocardial regression during outflow tract development. Dev. Dyn. 236, 671-683.

Kern, C. B., Wessels, A., McGarity, J., Dixon, L. J., Alston, E., Argraves, W. S., Geeting, D., Nelson, C. M., Menick, D. R. and Apte, S. S. (2010). Reduced versican cleavage due to Adamts9 haploinsufficiency is associated with cardiac and aortic anomalies. Matrix Biol. 29, 304-316.

Krantz, I. D., Smith, R., Colliton, R. P., Tinkel, H., Zackai, E. H., Piccoli, D. A., Goldmuntz, E. and Spinner, N. B. (1999). Jagged1 mutations in patients ascertained with isolated congenital heart defects. Am. J. Med. Genet. 84, 5660.

Lakkis, M. M. and Epstein, J. A. (1998). Neurofibromin modulation of ras activity is required for normal endocardial-mesenchymal transformation in the developing heart. Development 125, 4359-4367.

Leong, K. G., Niessen, K., Kulic, I., Raouf, A., Eaves, C., Pollet, I. and Karsan, A. (2007). Jagged1-mediated Notch activation induces epithelial-tomesenchymal transition through Slug-induced repression of E-cadherin. J. Exp. Med. 204, 2935-2948

Liao, P., Georgakopoulos, D., Kovacs, A., Zheng, M., Lerner, D., Pu, H., Saffitz, J., Chien, K., Xiao, R. P., Kass, D. A. et al. (2001). The in vivo role of p38 MAP kinases in cardiac remodeling and restrictive cardiomyopathy. Proc. Natl. Acad. Sci. USA 98, 12283-12288.

Liu, H., Kennard, S. and Lilly, B. (2009). NOTCH3 expression is induced in mural cells through an autoregulatory loop that requires endothelial-expressed JAGGED1. Circ Res 104, 466-475.

Loomes, K. M., Underkoffler, L. A., Morabito, J., Gottlieb, S., Piccoli, D. A., Spinner, N. B., Baldwin, H. S. and Oakey, R. J. (1999). The expression of Jagged1 in the developing mammalian heart correlates with cardiovascular disease in Alagille syndrome. Hum. Mol. Genet. 8, 2443-2449.

MacGrogan, D., Luna-Zurita, L. and de la Pompa, J. L. (2011). Notch signaling in cardiac valve development and disease. Birth Defects Res. A Clin. Mol. Teratol. 91, 449-459.

Mancini, S. J., Mantei, N., Dumortier, A., Suter, U., MacDonald, H. R. and Radtke, F. (2005). Jagged1-dependent Notch signaling is dispensable for hematopoietic stem cell self-renewal and differentiation. Blood 105, 2340-2342.

Manderfield, L. J., High, F. A., Engleka, K. A., Liu, F., Li, L., Rentschler, S. and Epstein, J. A. (2012). Notch activation of Jagged1 contributes to the assembly of the arterial wall. Circulation 125, 314-323.

Mathews, T. J. and MacDorman, M. F. (2011). Infant mortality statistics from the 2007 period linked birth/infant death data set. Natl. Vital Stat. Rep. 59, 1-30

McCright, B., Lozier, J. and Gridley, T. (2002). A mouse model of Alagille syndrome: Notch2 as a genetic modifier of Jag1 haploinsufficiency. Development $129,1075-1082$ 
McDaniell, R., Warthen, D. M., Sanchez-Lara, P. A., Pai, A., Krantz, I. D., Piccoli, D. A. and Spinner, N. B. (2006). NOTCH2 mutations cause Alagille syndrome, a heterogeneous disorder of the notch signaling pathway. Am. J. Hum. Genet. 79, 169-173.

McElhinney, D. B., Krantz, I. D., Bason, L., Piccoli, D. A., Emerick, K. M., Spinner, N. B. and Goldmuntz, E. (2002). Analysis of cardiovascular phenotype and genotype-phenotype correlation in individuals with a JAG1 mutation and/or Alagille syndrome. Circulation 106, 2567-2574.

Nemir, M. and Pedrazzini, T. (2008). Functional role of Notch signaling in the developing and postnatal heart. J. Mol. Cell. Cardiol. 45, 495-504.

Nigam, V. and Srivastava, D. (2009). Notch1 represses osteogenic pathways in aortic valve cells. J. Mol. Cell. Cardiol. 47, 828-834.

Noseda, M., McLean, G., Niessen, K., Chang, L., Pollet, I., Montpetit, R., Shahidi, R., Dorovini-Zis, K., Li, L., Beckstead, B. et al. (2004). Notch activation results in phenotypic and functional changes consistent with endothelial-to-mesenchymal transformation. Circ. Res. 94, 910-917.

Olson, E. N. (2006). Gene regulatory networks in the evolution and development of the heart. Science 313, 1922-1927.

Otto, C. M. (2009). Calcific aortic valve disease: outflow obstruction is the end stage of a systemic disease process. Eur. Heart J. 30, 1940-1942.

Penton, A. L., Leonard, L. D. and Spinner, N. B. (2012). Notch signaling in human development and disease. Semin. Cell Dev. Biol. 23, 450-457.

Person, A. D., Klewer, S. E. and Runyan, R. B. (2005). Cell biology of cardiac cushion development. Int. Rev. Cytol. 243, 287-335.

Raas-Rothschild, A., Shteyer, E., Lerer, I., Nir, A., Granot, E. and Rein, A. J. (2002). Jagged1 gene mutation for abdominal coarctation of the aorta in Alagille syndrome. Am. J. Med. Genet. 112, 75-78.

Radtke, F., Wilson, A., Stark, G., Bauer, M., van Meerwijk, J., MacDonald, H. R. and Aguet, M. (1999). Deficient T cell fate specification in mice with an induced inactivation of Notch1. Immunity 10, 547-558.

Red-Horse, K., Ueno, H., Weissman, I. L. and Krasnow, M. A. (2010). Coronary arteries form by developmental reprogramming of venous cells. Nature 464, 549-553

Rodríguez-Manzaneque, J. C., Westling, J., Thai, S. N., Luque, A., Knauper, V., Murphy, G., Sandy, J. D. and Iruela-Arispe, M. L. (2002). ADAMTS1 cleaves aggrecan at multiple sites and is differentially inhibited by metalloproteinase inhibitors. Biochem. Biophys. Res. Commun. 293, 501-508.

Runyan, R. B. and Markwald, R. R. (1983). Invasion of mesenchyme into threedimensional collagen gels: a regional and temporal analysis of interaction in embryonic heart tissue. Dev. Biol. 95, 108-114.

Rutenberg, J. B., Fischer, A., Jia, H., Gessler, M., Zhong, T. P. and Mercola, M. (2006). Developmental patterning of the cardiac atrioventricular canal by Notch and Hairy-related transcription factors. Development 133, 4381-4390.

Sandy, J. D., Westling, J., Kenagy, R. D., Iruela-Arispe, M. L., Verscharen, C., Rodriguez-Mazaneque, J. C., Zimmermann, D. R., Lemire, J. M., Fischer, J. W., Wight, T. N. et al. (2001). Versican V1 proteolysis in human aorta in vivo occurs at the Glu441-Ala442 bond, a site that is cleaved by recombinant ADAMTS-1 and ADAMTS-4. J. Biol. Chem. 276, 13372-13378.
Scheppke, L., Murphy, E. A., Zarpellon, A., Hofmann, J. J., Merkulova, A., Shields, D. J., Weis, S. M., Byzova, T. V., Ruggeri, Z. M., Iruela-Arispe, M. L. et al. (2012). Notch promotes vascular maturation by inducing integrinmediated smooth muscle cell adhesion to the endothelial basement membrane. Blood 119, 2149-2158.

Schroeder, H. E. and Listgarten, M. A. (2003). The junctional epithelium: from strength to defense. J. Dent. Res. 82, 158-161.

Somerville, R. P., Longpre, J. M., Jungers, K. A., Engle, J. M., Ross, M., Evanko, S., Wight, T. N., Leduc, R. and Apte, S. S. (2003). Characterization of ADAMTS-9 and ADAMTS-20 as a distinct ADAMTS subfamily related to Caenorhabditis elegans GON-1. J. Biol. Chem. 278, 9503-9513.

Soriano, P. (1999). Generalized lacZ expression with the ROSA26 Cre reporter strain. Nat. Genet. 21, 70-71

Srivastava, D. (2006). Making or breaking the heart: from lineage determination to morphogenesis. Cell 126, 1037-1048.

Thai, S. N. and Iruela-Arispe, M. L. (2002). Expression of ADAMTS1 during murine development. Mech. Dev. 115, 181-185.

Timmerman, L. A., Grego-Bessa, J., Raya, A., Bertrán, E., Pérez-Pomares, J. M., Díez, J., Aranda, S., Palomo, S., McCormick, F., Izpisúa-Belmonte, J. C. et al. (2004). Notch promotes epithelial-mesenchymal transition during cardiac development and oncogenic transformation. Genes Dev. 18, 99-115.

Trindade, A., Kumar, S. R., Scehnet, J. S., Lopes-da-Costa, L., Becker, J., Jiang, W., Liu, R., Gill, P. S. and Duarte, A. (2008). Overexpression of deltalike 4 induces arterialization and attenuates vessel formation in developing mouse embryos. Blood 112, 1720-1729.

van der Linde, D., Konings, E. E. M., Slager, M. A., Witsenburg, M., Helbing, W. A., Takkenberg, J. J. M. and Roos-Hesselink, J. W. (2011). Birth prevalence of congenital heart disease worldwide: a systematic review and meta-analysis. J. Am. Coll. Cardiol. 58, 2241-2247.

Vrijens, K., Thys, S., De Jeu, M. T., Postnov, A. A., Pfister, M., Cox, L., Zwijsen, A., Van Hoof, V., Mueller, M., De Clerck, N. M. et al. (2006). Ozzy, a Jag1 vestibular mouse mutant, displays characteristics of Alagille syndrome. Neurobiol. Dis. 24, 28-40.

Xue, Y., Gao, X., Lindsell, C. E., Norton, C. R., Chang, B., Hicks, C., GendronMaguire, M., Rand, E. B., Weinmaster, G. and Gridley, T. (1999). Embryonic lethality and vascular defects in mice lacking the Notch ligand Jagged1. Hum. Mol. Genet. 8, 723-730.

Yamamura, H., Zhang, M., Markwald, R. R. and Mjaatvedt, C. H. (1997). A heart segmental defect in the anterior-posterior axis of a transgenic mutant mouse. Dev. Biol. 186, 58-72.

Zavadil, J., Cermak, L., Soto-Nieves, N. and Böttinger, E. P. (2004). Integration of TGF-beta/Smad and Jagged1/Notch signalling in epithelial-to-mesenchymal transition. EMBO J. 23, 1155-1165

Zovein, A. C., Luque, A., Turlo, K. A., Hofmann, J. J., Yee, K. M., Becker, M. S., Fassler, R., Mellman, I., Lane, T. F. and Iruela-Arispe, M. L. (2010). beta1 integrin establishes endothelial cell polarity and arteriolar lumen formation via a Par3-dependent mechanism. Dev. Cell 18, 39-51. 